\title{
EXPERIENCE WITH THE CHROMIC OXIDE METHOD OF FECAL MARKING IN METABOLIC BALANCE INVESTIGATIONS \\ ()N HUMANS
}

\author{
BY L. G. WHITBY AND DAPHNE LANG
}

\begin{abstract}
(From the Department of Chemical Pathology, Postgraduate Medical School of London, and the Metabolic Unit Laboratory, Hammersmith Hospital, London, England)
\end{abstract}

(Submitted for publication November 2, 1959; accepted February 4, 1960)

In metabolic balance studies the assessment of the subject's state of balance is derived from estimates of the dietary intake and the excretion in the urine and feces of the constituent under investigation. It is relatively simple to measure the dietary and urinary components, but estimation of the fecal component is more liable to error because of difficulties in securing a quantitative fecal collection. Where a significant proportion of the dietary intake is recoverable from the feces, for instance in studies of calcium balances, accurate fecal collections are of prime importance.

Many investigators employ the "time-marker" method for obtaining quantitative fecal collections giving, for instance, two doses of carmine as a marker, collecting the feces passed between the time of appearance in the feces of the first and second doses of marker, and relating this collection to the diet consumed and urine passed in the interval between the giving of the markers. The success of this method depends upon the clear recognition of the marker in the feces and the accurate collection of all feces passed during the period of study. In investigations in which no marker is employed (i.e., simple "time-collection" studies), accuracy also depends upon the subject's having a regular pattern of colonic emptying.

The "inert indicator" method provides an alternative means of estimating the fecal component in balance studies, and it has the big advantage of avoiding the dependence on quantitative fecal collections. It was first used in experiments with animals, and a summarized description of the "Edin indicator method," which used chromium sesquioxide $\left(\mathrm{Cr}_{2} \mathrm{O}_{3}\right)$, was given by Edin, Kihlén and Nordfeldt (1). The theory of the method has been discussed by Stanley and Cheng (2). Various substances have been tried as indicators, but all have to fulfill the following criteria: they should neither be absorbed from nor be chemically altered in the digestive tract (and so be fully recoverable from the feces); they should be nontoxic and should not interefere with the processes of digestion; they should be uniformly dispersed in the feces, after a sufficient time for attainment in the bowel of a steady state with respect to the indicator; and they should be readily estimated quantitatively in feces.

Several indicators have been used in a wide range of investigations on different species of animals (e.g., 3-5), but the principal indicators employed in human studies have been $\mathrm{Cr}_{2} \mathrm{O}_{3}(1,2$, 6-8) and polyethylene glycol $(9,10)$. Animal experiments had shown that $\mathrm{Cr}_{2} \mathrm{O}_{3}$ met all the required criteria, and this has been confirmed for man in the above accounts of its application and in our experience. These earlier accounts all had shown that its use in man provided a valid basis on which to express fecal analytical data, when compared with "time-collection" studies; one investigation (7) also showed that fecal analyses based on $\mathrm{Cr}_{2} \mathrm{O}_{3}$ compared satisfactorily with carmine "time-marker" studies. However, previous work on the application of $\mathrm{Cr}_{2} \mathrm{O}_{3}$ to humans had involved only small numbers of volunteers or patients: i.e. three volunteers (6), six volunteers (7), three volunteers and two patients $(2,8)$, while Edin and associates (1) merely stated that they had applied the method to humans.

This article describes the more extensive application of $\mathrm{Cr}_{2} \mathrm{O}_{3}$ as an inert indicator in balance studies on man. No comparison has been made with polyethylene glycol, but $\mathrm{Cr}_{2} \mathrm{O}_{3}$ is theoretically more suitable as an inert indicator, since it is a single chemical substance, whereas polyethylene glycol is a mixture of polymers which do not all behave identically in the method used for their estimation (11). Polyethylene glycol has been mainly used in man as an inert reference substance in studies of intestinal absorption; unlike 
$\mathrm{Cr}_{2} \mathrm{O}_{3}$, it is suitable for aspiration via a narrowlumen gastrointestinal tube $(9,10)$.

\section{METHODS}

The results presented here have been derived from studies on 4 volunteers and 36 patients, all of whom took capsules of $\mathrm{Cr}_{2} \mathrm{O}_{3}$ during calcium balance investigations (the technique has also been used in conjunction with fat, nitrogen and potassium balance studies in this metabolic unit).

Regimen. Subjects received a low calcium diet, and calcium supplements were provided in tablet form, as recommended by Reifenstein, Albright and Wells (12). The diet was prepared in a separate kitchen by a trained dietitian and was analyzed periodically. Subjects were placed on their particular regimen for a preliminary (or pre-investigation) period of 3 days, after which balance investigations commenced. Results were calculated on the basis of a pair of 3-day collections on each regimen; if the conditions of balance study were then altered, there was a transitional period of 3 days followed by another pair of 3-day collections. Purgatives were used whenever indicated in order to secure a bowel action at least on alternate days. Fecal collections closed at 8 a.m.; if a subject had not had a spontaneous bowel action by this time on the last day of the balance investigations, an enema was administered and its result added to the fecal collection for that period.

Capsules of $\mathrm{Cr}_{2} \mathrm{O}_{3}$ were taken 3 times daily, one with each of the main meals, beginning when the subjects started their balance regimen. Capsules were preferred to other means of $\mathrm{Cr}_{2} \mathrm{O}_{3}$ administration because of the known highly abrasive properties of the compound (a trial batch of tablets, specially prepared industrially, had to be rejected because of their friability and marked variation in $\mathrm{Cr}_{2} \mathrm{O}_{3}$ content).

Balance studies rejected. Four balances could not be analyzed. One volunteer developed appendicitis and had to withdraw from study; one patient did not cooperate in taking $\mathrm{Cr}_{2} \mathrm{O}_{3}$ capsules; another did not adhere to his diet; and a third patient was severely constipated.

Purification of $\mathrm{Cr}_{2} \mathrm{O}_{3}$. Commercial $\mathrm{Cr}_{2} \mathrm{O}_{3}$ contains small amounts of dichromate. Two hundred $\mathrm{g}$ chromic oxide, green (B.D.H. ${ }^{1}$ ) was shaken with successive 800 $\mathrm{ml}$ quantities of 10 per cent hydrochloric acid until the supernatant was colorless; it was then washed with distilled water and dried at $600^{\circ} \mathrm{C}$ for 24 hours. Capsules were filled with $500 \pm 2 \mathrm{mg} \mathrm{Cr}_{2} \mathrm{O}_{3}$.

Preparation of specimens for analysis. Diets and feces were processed as described by King and Wootton (13). Samples of homogenized feces were taken as soon as blending had ceased, to avoid sedimenting of $\mathrm{Cr}_{2} \mathrm{O}_{3}$ which has a high specific gravity (14). The fecal samples were dried and then ground to a fine powder. Urine collections were made over 24-hour periods and samples pooled for analysis to correspond with the periods of fecal collections.

\footnotetext{
1 British Drug Houses.
}

Standard solutions. Potassium dichromate (AR) was heated for 30 minutes at $180^{\circ} \mathrm{C}$ and cooled in a desiccator. A $0.1 \mathrm{~N}$ solution was prepared in $2 \mathrm{~N}$ sulfuric acid.

Ammonium ferrous sulfate: an approximately $0.1 \mathrm{~N}$ solution was prepared in $2 \mathrm{~N}$ sulfuric acid and standardized daily against potassium dichromate, using $0.5 \mathrm{ml}$ $\mathrm{N}$-phenyl anthranilic acid solution as indicator (15).

Estimation of $\mathrm{Cr}_{2} \mathrm{O}_{3}$ in feces. One-half $\mathrm{g}$ samples of dried feces were digested with $20 \mathrm{ml}$ AR concentrated nitric acid until all of the organic matter was oxidized (the flask contents were then a suspension of green $\mathrm{Cr}_{2} \mathrm{O}_{3}$ in a clear liquid). Digestions were carried out in $250 \mathrm{ml}$ quartz Erlenmeyer flasks on a hot plate in a fume cupboard and bauxalite boiling chips were added; further additions of nitric acid were made, if necessary, to avoid evaporation to dryness. Twenty $\mathrm{ml}$ AR perchloric acid (60 per cent; sp gr 1.54) was then added and heating recommenced (behind a screen of Perspex) until $\mathrm{Cr}_{2} \mathrm{O}_{3}$ had been converted to dichromate. The conditions of the digestion of specimens with nitric and perchloric acids conformed to the recommendations of the Analytical Methods Committee concerning the use of perchloric acid (16), and the practical directions of Smith (17) were followed; these articles should be consulted since there is a risk of serious explosion.

For the final estimation of dichromate, $50 \mathrm{ml} 6 \mathrm{~N}$ sulfuric acid, $20 \mathrm{ml}$ standardized ammonium ferrous sulfate (more is occasionally necessary) and $0.5 \mathrm{ml}$ indicator are added, to the flask contents (final volume approximately $150 \mathrm{ml}$ ). The excess of ammonium ferrous sulfate is estimated by back-titration with potassium dichromate added dropwise from a buret. The flask is shaken continuously but the endpoint is not so clear as in the standardization titration; it is marked by the disappearance of green color from the solution and the appearance of a slate-like indeterminate shade which develops, after standing for a few minutes, into a cherry color. The conditions of the titration conform to the recommendations of earlier workers $(15,18,19)$, and the reason for the slow development of the indicator's change in color at the endpoint has not been discovered. Furness (18) and Stockdale (19) observed that, although many factors interfered with the sharpness of the endpoint titration, the accuracy of the determination surprisingly did not seem to suffer, and they regarded the choice of indicator as largely a matter of personal preference; this has been our experience also.

Accuracy of $\mathrm{Cr}_{2} \mathrm{O}_{3}$ determinations. Known amounts ( 10 to $50 \mathrm{mg}$ ) of purified $\mathrm{Cr}_{2} \mathrm{O}_{3}$ were converted to dichromate and estimated; the recovery was $98.4 \pm 2$ per cent (mean $\pm \mathrm{SD}$ mean; 21 determinations). Similar quantities of $\mathrm{Cr}_{2} \mathrm{O}_{3}$ were added to $0.5 \mathrm{~g}$ samples of dried feces (specimens from patients who had not received $\mathrm{Cr}_{2} \mathrm{O}_{3}$ ) and the recovery was $98.6 \pm 1.9$ per cent (mean $\pm \mathrm{SD}$ mean; 25 determinations). Duplicated analyses for $\mathrm{Cr}_{2} \mathrm{O}_{3}$ in fecal specimens from patients who had received $\mathrm{Cr}_{2} \mathrm{O}_{3}$ agreed with a root mean square difference of 1.2 per cent ( 21 duplicated analyses).

The results of these recovery experiments are satis- 
factory, considering that the digestions are carried out in simple apparatus. Gorsuch (20) obtained similar figures when investigating the recovery of chromium from organic and biological material by a radiochemical technique; he fitted each digestion flask with a splashhead leading to a receiver, recovered 2 per cent of the radioactivity in the distillate, and attributed this loss from the digestion flask to the formation of volatile chromyl chloride.

In the present investigation, volunteers and patients have ingested $1.50 \mathrm{~g} \mathrm{Cr}_{2} \mathrm{O}_{3}$ daily, but in the calculations which follow, this figure has been modified to $1.48 \mathrm{~g}$ to correct for the observed incomplete recovery of $\mathrm{Cr}_{2} \mathrm{O}_{3}$ in the analytical procedure.

Determinations of calcium. These were made with a flame-spectrophotometer (21). $\mathrm{Cr}_{2} \mathrm{O}_{3}$ is unaffected by the dry-ashing procedure (13) employed in these analyses, but its presence in the residue after ashing does not interfere with the estimation of fecal calcium in the flame-spectrophotometer.

Uniformity of mixing of $\mathrm{Cr}_{2} \mathrm{O}_{3}$ in feces at the time of evacuation. Irwin and Crampton (7) made a pilot study of one volunteer who received a shredded wheat diet; $\mathrm{Cr}_{2} \mathrm{O}_{3}$ was given in various ways at mealtimes, but unmixed with the diet. They found that thrice daily administration of $\mathrm{Cr}_{2} \mathrm{O}_{3}$ resulted in uniform mixing of the index substance in the feces at the time of evacuation, whereas once daily dosage did not.

In the present investigation duplicate samples of feces from 4 patients have been analyzed; the samples were taken from the beginning and end of a single fecal evacuation and the wet specimens were used directly in the procedure for estimating $\mathrm{Cr}_{2} \mathrm{O}_{3}$. The results of these 4 paired analyses agreed with a root mean square difference of 1.6 per cent, and it was concluded that thrice daily dosage with capsules of $\mathrm{Cr}_{2} \mathrm{O}_{3}$ gave satisfactory mixing of the indicator in the feces.

\section{Explanation For All Figures}

In each figure data are included about fecal output, calcium intake and excretion, and recovery of chromium sesquioxide $\left(\mathrm{Cr}_{2} \mathrm{O}_{3}\right)$ from the feces. These data are presented under two headings ( $\mathrm{A}$ and $\mathrm{B}$ ) and the individual periods of balance (indicated by Roman numerals) correspond in the two parts of each figure.

Each balance period is of 3 days' duration, and the subject begins the balance regimen and the ingestion of $\mathrm{Cr}_{2} \mathrm{O}_{3}$ at the start of Period I. Specimens are collected for calcium estimation from Period II onward, until the balance regimen is ended; if the regimen is altered, there is a transitional period in which no calcium analyses are performed, followed by further collection periods.

Upper pair of histograms. A : The average daily weight of fecal dry matter in each period (obtained by drying a representative sample of feces). B: The theoretical daily weight of fecal dry matter in each period, or mean stool flow (2); this is derived from measurement of the fecal $\mathrm{Cr}_{2} \mathrm{O}_{3}$ content, and is the weight of fecal dry matter that would contain the same quantity of $\mathrm{Cr}_{2} \mathrm{O}_{3}$ as the daily intake (i.e., $1.50 \mathrm{~g} \mathrm{Cr}_{2} \mathrm{O}_{3}$ per day).

Lower pair of histograms. These show the calcium balance data plotted according to the conventions of Reifenstein and colleagues (12). The dietary intake is measured downward from the baseline and is represented by the lowest horizontal line in these histograms. The calcium content of the excreta is built upward from this level (fecal component hatched, urinary component unshaded). The state of balance is shown by the height of each completed histogram relative to the baseline; a positive balance is represented by a gap between the top of a histogram and the baseline, and a negative balance exists when the histogram reaches above the level of the baseline.

The state of balance for any period is different in the corresponding parts of each figure; this is due to the different contributions made by the fecal components in the two methods of expressing the calcium balance data. In $A$ the fecal calcium excretion is the product of the fecal calcium concentration (in milliequivalents per gram dried feces) and the average daily weight of feces, whereas in B it is the product of the fecal calcium concentration and the mean stool flow.

Unpaired histogram (bottom right). This shows the average daily recovery of $\mathrm{Cr}_{2} \mathrm{O}_{3}$ from the feces for each period; it is the product of the fecal $\mathrm{Cr}_{2} \mathrm{O}_{3}$ content and the average daily fecal dry weight.

\section{RESULTS}

Many of the ways in which use of an inert indicator modifies and supplements balance data will be considered in relation to the figures, in which the results of four representative balance studies are presented. A general explanation for all the figures has been given, and this should be studied before referring to the individual figure legends.

\section{The need for the use of an inert indicator}

1) To measure individual irregularities in bowel habit. The degree of variation in fecal output is demonstrated by examination of the recovery of $\mathrm{Cr}_{2} \mathrm{O}_{3}$ from the feces in single balance periods. Although the average recovery of $\mathrm{Cr}_{2} \mathrm{O}_{3}$ from feces during actual periods of balance investigation approximately equals the daily intake of inert indicator, considerable variation from this figure is observed between the values obtained for individual collection periods (e.g., Figures 1, 3 and 4 ; bottom right histograms).

The balance studies reviewed here have been conducted on the basis of paired three-day collection periods, and 52 such balance investigations 
(from 33 patients and 3 volunteers) have been examined to assess the recovery of $\mathrm{Cr}_{2} \mathrm{O}_{3}$ during the periods of balance study (i.e., the pre-investigation and post-balance figures for excretion of $\mathrm{Cr}_{2} \mathrm{O}_{3}$ are not being considered here). The average recovery of $\mathrm{Cr}_{2} \mathrm{O}_{3}$ from the feces for the first period of each pair of balance periods was 1.42 (range 0.60 to 2.53 ) g per day, and for the second period it was 1.38 (range 0.70 to 2.12 ) g per day; the theoretical recovery, allowing for losses of $\mathrm{Cr}_{2} \mathrm{O}_{3}$ during the analyses, was $1.48 \mathrm{~g}$ per day.

This wide variation in daily recoveries of $\mathrm{Cr}_{2} \mathrm{O}_{3}$ is a measure of the inconstancy of human fecal output when collection periods are of three days' length. Many investigators use neither carmine marker nor inert indicator, but employ timed collections of feces extending over six days, in order to reduce the effect of individual variation in daily fecal output. Output variation may still be considerable, even when feces are collected over sixday periods, as is shown by calculation of the average daily recovery of $\mathrm{Cr}_{2} \mathrm{O}_{3}$ from the feces in the above 52 balance investigations, treating each pair of three-day collections as one sixday collection; the average recovery was 1.40 (range 0.70 to 1.96 ) $\mathrm{g} \mathrm{Cr}_{2} \mathrm{O}_{3}$ per day during the six-day periods.

2) To correct for the incompleteness of fecal collections. The completeness of fecal collections in this unit has been assessed by determining the total recovery of $\mathrm{Cr}_{2} \mathrm{O}_{3}$ from the feces of six patients who were kept in the unit for at least three days after their balance investigations had ended and after they had stopped taking $\mathrm{Cr}_{2} \mathrm{O}_{3}$. Feces passed throughout the period of $\mathrm{Cr}_{2} \mathrm{O}_{3}$ administration and for three days after its cessation were collected as completely as possible and analyzed for $\mathrm{Cr}_{2} \mathrm{O}_{3}$. The total recoveries of $\mathrm{Cr}_{2} \mathrm{O}_{3}$ from these six patients were 88, 91, 92, 93, 95 and 98 per cent of the administered dose; the graph accompanying the bottom right histogram in Figure 1 shows the progress of $\mathrm{Cr}_{2} \mathrm{O}_{3}$ recovery from the feces of the last of these patients.

Stanley and Cheng $(2,8)$ used a liquid diet in which $\mathrm{Cr}_{2} \mathrm{O}_{3}$ was uniformly dispersed; in one of their subjects excretion of the indicator was almost complete 72 hours after the last dose of $\mathrm{Cr}_{2} \mathrm{O}_{3}$. Irwin and Crampton (7) gave their pilot subject a diet of shredded wheat and administered $\mathrm{Cr}_{2} \mathrm{O}_{3}$ separately but at mealtimes; they found that passage of $\mathrm{Cr}_{2} \mathrm{O}_{3}$ in the feces had ended within 48 hours of the last ingestion. Two of the above six patients were retained for six days after the last capsule of $\mathrm{Cr}_{2} \mathrm{O}_{3}$ had been administered;
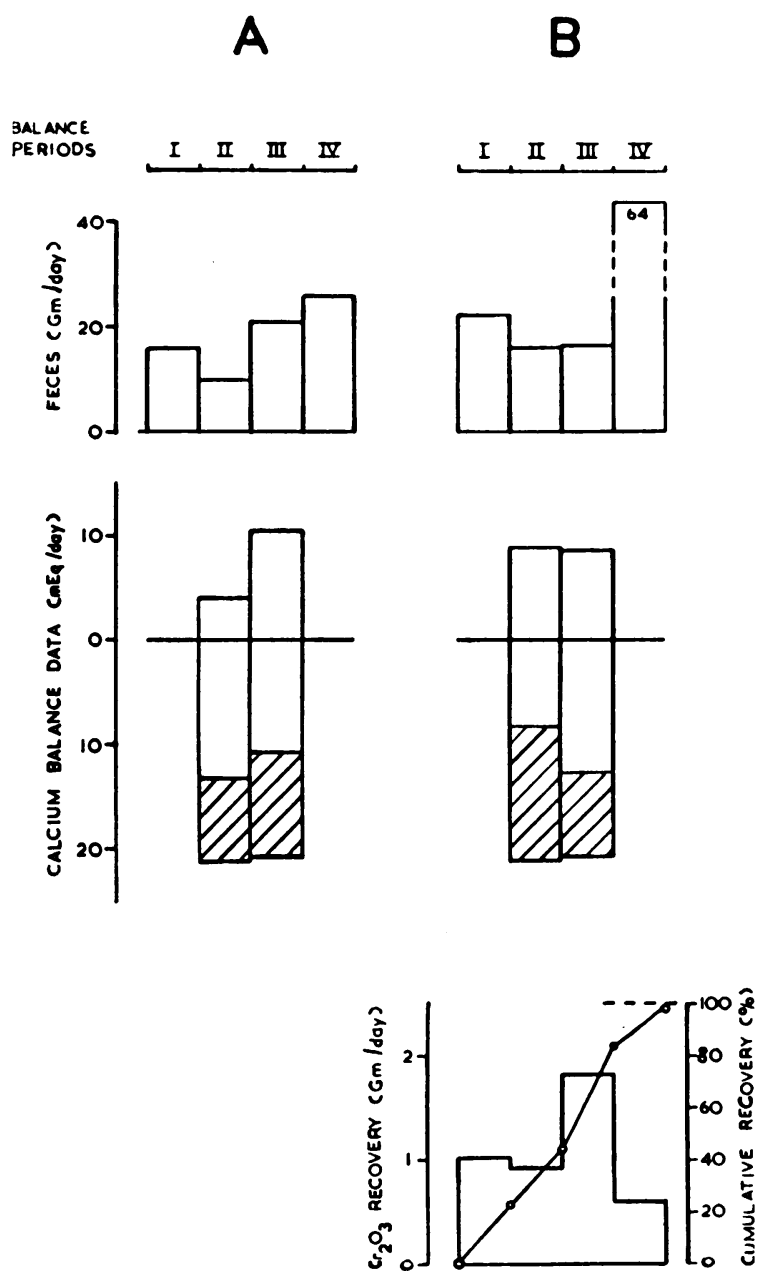

Fig. 1. Response of a patient to a low Calcium INTAKe. $\mathrm{Cr}_{2} \mathrm{O}_{3}$ was administered during Periods $\mathrm{I}$ to III inclusive; the actual times of balance study were Periods II and III, but feces were collected for $\mathrm{Cr}_{2} \mathrm{O}_{3}$ analysis for 3 days before and 3 days after the balance study proper. The mean stool flow (top histogram, B) has real meaning only while $\mathrm{Cr}_{2} \mathrm{O}_{3}$ is being administered, and once the steady state has been attained (Periods II and III), when it should be compared with the average daily fecal dry weight. The histograms for the mean stool flow follow the pattern shown in this figure in all balance investigations, falling to a relatively constant value with attainment of the steady state, and rising again when dosage with $\mathrm{Cr}_{2} \mathrm{O}_{3}$ ceases. The graph accompanying the bottom right histogram shows the cumulative recovery of $\mathrm{Cr}_{2} \mathrm{O}_{3}$ from the feces during and after administration of $\mathrm{Cr}_{2} \mathrm{O}_{3}$. See "Explanation For All Figures" in text. 


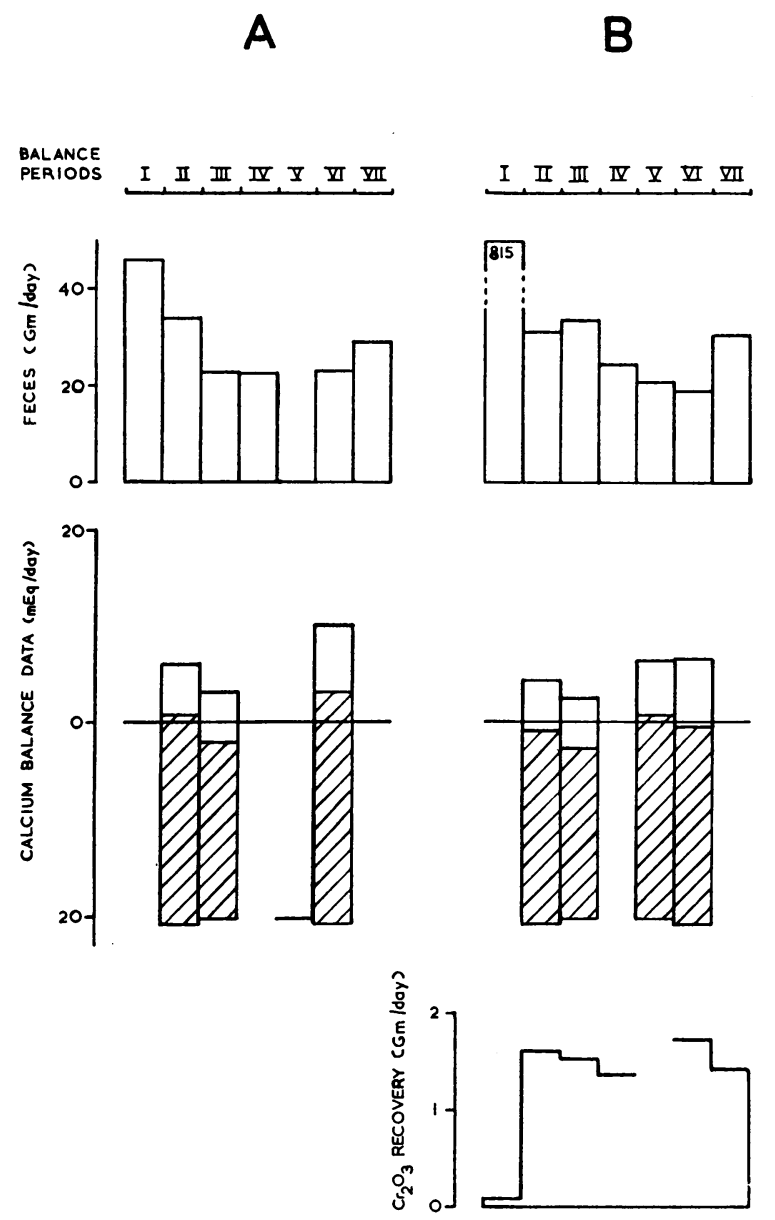

Fig. 2. Response of a patient to a low CAlcium INTAKE. Two different balance regimens have been employed; in Period IV dosage with $9 \alpha$-fluorocortisol commenced. No calcium analyses were made in Periods I or IV, during which the patient was adjusting to each regimen. Dosage with $\mathrm{Cr}_{2} \mathrm{O}_{3}$ ceased after period VI. Three of the histograms are incomplete. In Period $\mathrm{V}$ feces were collected and processed routinely (i.e., a "complete" collection was made); a representative sample was taken, but the data on weighings of the wet feces were lost, accounting for the gaps in $\mathrm{A}$ and in the bottom histogram of B. Introduction of $9 \alpha$-fluorocortisol resulted in a marked change in the mean stool flow (compare Periods II and III of the top histogram, B, with Periods V and VI of the same histogram); a new steady state has been attained in Period V. This figure shows how the use of an inert indicator can act as an insurance policy against accidental loss of data; the calcium balance data in $\mathrm{B}$ are complete, and the subject's state of balance is accurately determinable.

the feces of these post-balance periods were processed as two three-day collections in the usual way. No trace of $\mathrm{Cr}_{2} \mathrm{O}_{3}$, was detected in the feces of these later periods. This suggests that three days was a sufficiently long time (with the dietary and nursing regimen employed here) for feces to be collected after stopping $\mathrm{Cr}_{2} \mathrm{O}_{3}$ administration in order to assess the total recovery of indicator from the stools.

It may be concluded that in this metabolic unit a "quantitative" fecal collection is only 93 per cent complete. Assuming that "quantitative" fecal collections in other metabolic units are similarly incomplete, these studies reveal a minor source of error in balance investigations for which an inert indicator can correct, but for which no correction is possible in simple "time-collection" or "time-marker" studies.

\section{The attainment of a steady state for excretion of $\mathrm{Cr}_{2} \mathrm{O}_{3}$}

When a subject receives $\mathrm{Cr}_{2} \mathrm{O}_{3}$ the fecal content rises from zero to a level which becomes fairly constant for a given individual on a particular balance regimen; expressed in another way, the subject's mean stool flow falls, with appearance of $\mathrm{Cr}_{2} \mathrm{O}_{3}$ in the feces, and becomes constant, to within 15 per cent of a mean value (see below) for the particular regimen. When dosage with $\mathrm{Cr}_{2} \mathrm{O}_{3}$ ceases, it continues to be excreted for a time, and a value for the "mean stool flow" can still be calculated although it has ceased to have any real meaning. The general pattern followed by the mean stool flow in any balance investigation is illustrated in Figures 1 and 2 (top right histograms).

The time needed for fecal excretion of $\mathrm{Cr}_{2} \mathrm{O}_{3}$ to become steady depends partly upon the dietary regimen and partly on the individual. Stanley and Cheng $(2,8)$, using $\mathrm{Cr}_{2} \mathrm{O}_{3}$ dispersed uniformly in a liquid diet, found that their subjects attained steady levels of fecal $\mathrm{Cr}_{2} \mathrm{O}_{3}$ excretion within 48 hours, and Irwin and Crampton (7) found that the steady state was attained with equal rapidity under their conditions. With our subjects a steady level of $\mathrm{Cr}_{2} \mathrm{O}_{3}$ excretion has failed to be attained within 72 hours of starting $\mathrm{Cr}_{2} \mathrm{O}_{\text {: }}$ dosage in approximately one quarter of the balances. To reach this conclusion, the 52 balance investigations listed above were examined to compare the percentage difference between fecal clry weight figures for the individual periods in each of a pair of balance periods, before and after cor- 
rection of these figures in terms of the $\mathrm{Cr}_{2} \mathrm{O}_{3}$ output of the feces (i.e., the comparison which is made between the upper pair of histograms in each of the figures). With the uncorrected data the mean difference in fecal dry weight between periods was 31.4 per cent (difference between pairs of data expressed as a percentage of the mean value; range 0 to 84 per cent), and with the corrected data the difference was 12.8 per cent (range 0 to 37.3 per cent). With extended balance investigations it was noted that the mean stool flow stayed constant, to within 15 per cent of the mean value (e.g., Figure 3), unless the balance regimen was altered (e.g., Figure 2); a change of regimen sometimes caused a temporary large change in the mean stool flow, but a new steady state was always attained within 72 hours, i.e., by the end of the transitional period.

A degree of agreement of 15 per cent about the average value of the mean stool flow for pairs of balance periods on a given regimen is now applied retrospectively as a criterion of whether a patient had reached a steady state with respect to $\mathrm{Cr}_{2} \mathrm{O}_{3}$ in the first period of that balance investigation. As already noted, with a three-day preinvestigation period several of our patients did not meet this criterion, and latterly these preinvestigation periods have been lengthened to five days; so far ten patients have been investigated with this modified regimen, and the variation in mean stool flow has satisfied the above arbitrary criterion in all cases. Failure of the mean stool flow to attain a steady value may reflect an incomplete adjustment of the bowel to a balance regimen (e.g., because a new diet has caused a change in the intestinal flora) or failure of the fecal output of $\mathrm{Cr}_{2} \mathrm{O}_{3}$ to reach a steady value; in either case it means that the fecal component of the calcium balance data from such periods cannot be satisfactorily corrected in terms of the mean stool flow, since it is unsound to correct analytical data by the inert indicator technique until the patient has become adjusted both to the indicator and to the particular balance regimen.

Applying this criterion for the attainment of a steady level of $\mathrm{Cr}_{2} \mathrm{O}_{3}$ excretion to the above 52 balance investigations, 37 were acceptable. In these 37 selected balances the mean difference in uncorrected fecal weight data between periods was 32.2 (range 1.1 to 84 ) per cent, which com- pared with a difference of 6.4 (range 0 to 13 ) per cent between the mean stool flow for individual periods.

\section{Calcium balance data}

The upper pairs of histograms in the figures show how the use of $\mathrm{Cr}_{2} \mathrm{O}_{3}$ has an "averaging" effect on the fecal weight data, and the lower pairs of histograms (e.g., Figures 1 and 3) show how application of this averaging effect improves the agreement between the results of individual bal-

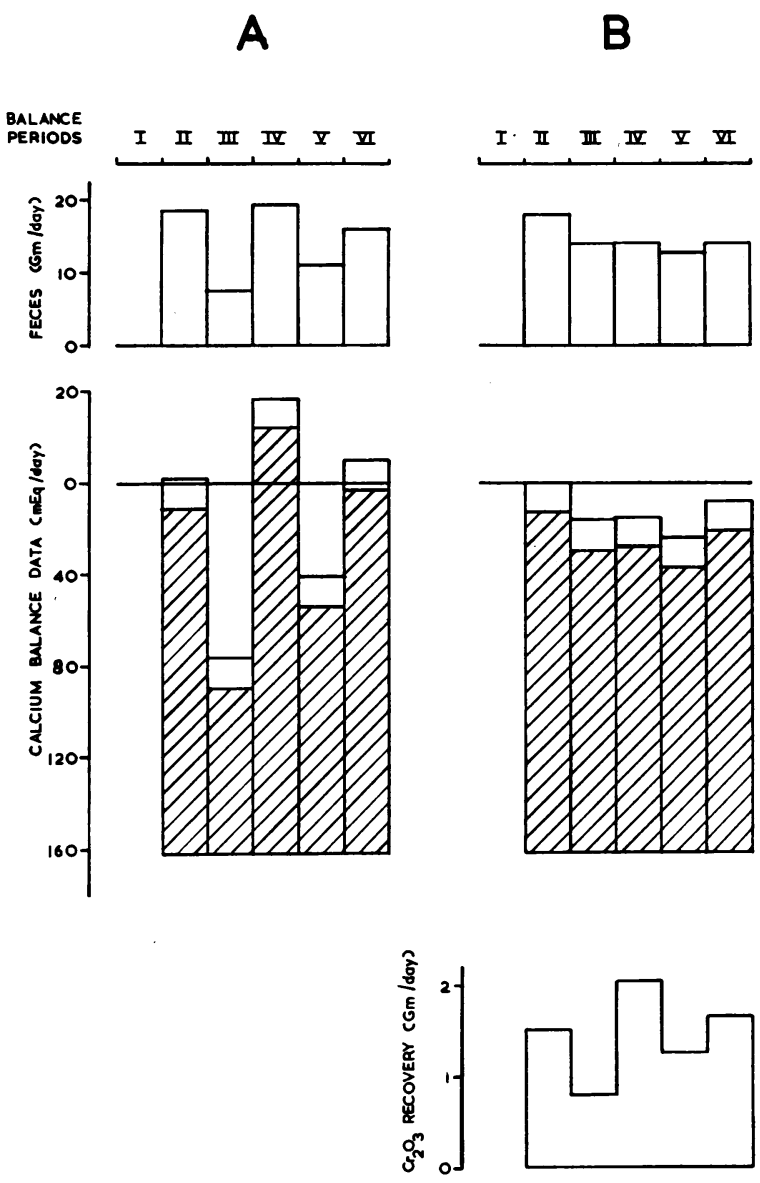

Fig. 3. Response of a patient to a high calcium INTAKE. The average daily fecal dry weight (top histogram, A) shows considerable variation from period to period when compared with the mean stool flow (top histogram, B). This variation is responsible for the marked fluctuation in the state of calcium balance (lower histogram, A), whereas in the corresponding histogram (B) there is little variation between periods, and the true state of calcium balance is accurately determinable. No data are available for fecal $\mathrm{Cr}_{2} \mathrm{O}_{3}$ content either before or after the actual periods of balance investigation. 


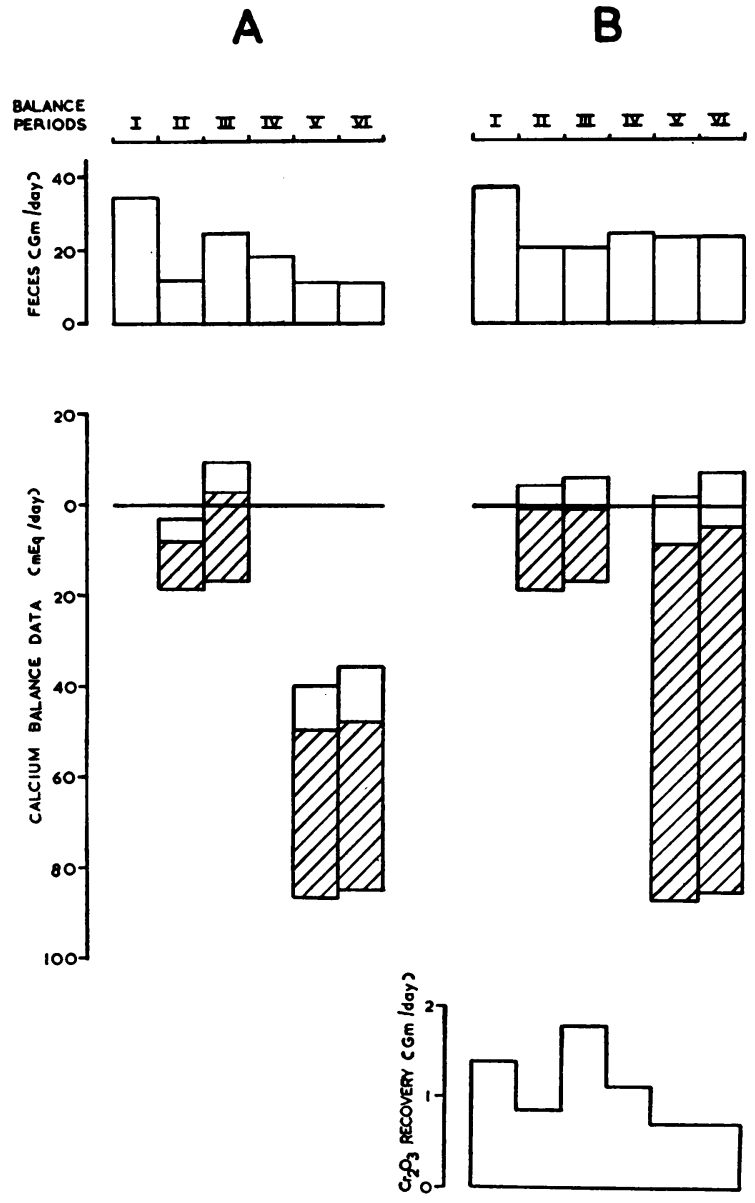

Fig. 4. Response of a patient to a low CAlcium INTAKE, FOLLOWED BY RESPONSE TO A HIGH CALCIUM INTAKE. No analyses for calcium were made in Periods I or IV, during which the patient was adjusting to the two balance regimens. Change of regimen in this patient has resulted in only a small change of mean stool flow (compare Periods II and III of the top histogram, $\mathrm{B}$, with Periods V and VI). The patient was moderately constipated during Periods $\mathrm{V}$ and VI, which accounted for the small fecal calcium excretion in $\mathrm{A}$; use of the inert indicator completely altered the interpretation of this part of the balance investigation (B). A similar result would have been obtained if the indicator had been used to assess the fecal calcium component of a random sample from each of these last two periods. No data are available for fecal $\mathrm{Cr}_{2} \mathrm{O}_{3}$ content after Period VI, when the balance investigation ceased.

ance periods. Considering the same 52 unselected balance investigations, the mean difference between uncorrected estimates of fecal calcium excretion in the pairs of balance periods was 38.4 (range 0 to 136) per cent, compared with a mean difference of 18.9 (range 1 to 78.2) per cent ob- tained when correction was applied for $\mathrm{Cr}_{2} \mathrm{O}_{3}$ excretion. If the 15 balances are rejected in which excretion of $\mathrm{Cr}_{2} \mathrm{O}_{3}$ does not meet the standard of steadiness proposed above, these values for the mean differences become 32.8 (range 0 to 136) per cent and 15.3 (range 1 to 70.6) per cent for uncorrected and corrected fecal calcium estimations, respectively. The agreement between corrected fecal calcium estimations is less than that between the mean stool flow values for pairs of periods, but this is due to the presence of additional sources of error in the former comparison, which is dependent upon the accuracy of the dietary intake and of the fecal calcium estimations, in addition to the accuracy of the analyses for $\mathrm{Cr}_{2} \mathrm{O}_{3}$.

\section{Random sampling}

In animal investigations an inert indicator is often used to enable fecal analyses to be performed on "grab" or random, samples. $\mathrm{Cr}_{2} \mathrm{O}_{3}$ has not been used for this purpose in the present work, but Figures 2 and 4 illustrate two ways in which the use of the inert indicator technique can compensate for incompleteness of fecal data. In Figure 3 , Period $\mathrm{V}$, the gaps in the histograms are due to loss of weight data concerned with the preparation of the specimen of dried feces; the calcium excretion data in Figure $2 \mathrm{~B}$ are complete, however because the only figures necessary for the fecal calculations are estimates of the calcium and $\mathrm{Cr}_{2} \mathrm{O}_{3}$ content of portions of the same specimen of feces, and a knowledge of the daily intake of $\mathrm{Cr}_{2} \mathrm{O}_{3}$ (2). This type of calculation underlies the use of the inert indicator technique in analyses of random samples, whenever feces cannot be collected quantitatively, but the major assumption then made is that the sample which has been "grabbed" for analysis is representative of the entire fecal output of a balance period.

In Figure 4 the calcium balance data for $\mathrm{Pe}$ riods $\mathrm{V}$ and $\mathrm{VI}$ have been modified from a strongly positive state of balance (in part A) into a steady, slight negative balance (in part B). The recovery of $\mathrm{Cr}_{2} \mathrm{O}_{3}$ in each of these periods was $0.70 \mathrm{~g}$ per day; this low value could have been due to accidental loss of approximately 50 per cent of the fecal collection from each period, but was in fact due to the patient's becoming 
moderately constipated. In a time-marker study the feces passed in Period VI would have been (correctly) allocated to the second half of $\mathrm{Pe}$ $\operatorname{riod} \mathrm{V}$, and the patient would have been retained in hospital until the feces belonging to Period VI had been collected; use of $\mathrm{Cr}_{2} \mathrm{O}_{3}$ avoided the necessity for an indeterminable stay in hospital, and the agreement between the values for the mean stool flow in Periods V and VI showed that the patient had adjusted to the changed regimen. The low recoveries of $\mathrm{Cr}_{2} \mathrm{O}_{3}$ in these two periods could alternatively have been due to loss of fecal material, but the use of the inert indicator would still have produced similar results (with the assumption that the feces analyzed were "representative"), whereas balance studies conducted on a simple time-collection or a time-marker basis would have been incomplete for these periods, or would have had to be calculated on a theoretical basis (12).

\section{Side effects}

No side effects attributable to the administration of $\mathrm{Cr}_{2} \mathrm{O}_{3}$ have been observed. It is possible, however, that $\mathrm{Cr}_{2} \mathrm{O}_{3}$ was responsible for the development in one volunteer of symptoms and signs suggesting a diagnosis of pelvic appendicitis. At laparotomy the appendix appeared normal, and histologically it was normal. The lumen of the appendix contained a fecalith which, unfortunately, was not preserved for analysis. The interest of this case lies in the fact that $\mathrm{Cr}_{2} \mathrm{O}_{3}$ ( $\mathrm{sp}$ gr 5.21 ) is more dense than barium sulfate ( $\mathrm{sp} \mathrm{gr}$ 4.50) (14), and there have been rare examples of acute appendicitis directly attributed to the use of barium contrast materials in X-ray examinations $(22,23)$.

\section{DISCUSSION}

The inert indicator method has been used here primarily to correct for the variation in the amount of feces excreted from day to day by humans during metabolic balance studies, and to correct for any incompleteness in "complete" fecal collections. The data for the recovery of $\mathrm{Cr}_{2} \mathrm{O}_{3}$ from the feces show the magnitude of the variability in fecal output, both when calculated over three-day and sixday periods of balance study, and the ability to correct for this variation is one of the chief ad- vantages of the inert indicator method over analyses based on simple time-collections of feces. By improving the agreement between individual periods in a balance investigation (e.g., Figure 3 ), it enables a better assessment to be made of the accuracy with which the subject's state of balance has been determined.

Use of the indicator to correct for incomplete fecal collections has amounted to an insurance against certain mistakes that occasionally occur and which can ruin a balance investigation based on simple "time-collection" or on "time-marker" studies. Two examples have been considered (Figures 2 and 4), but no detailed assessment has been made of the use of $\mathrm{Cr}_{2} \mathrm{O}_{3}$ to enable the fecal component in human balance investigations to be estimated by analysis of random samples. In animal work $\mathrm{Cr}_{2} \mathrm{O}_{3}$ has often been used as the basis for random analyses, but Kane, Jacobson and Moore (3) stressed that it can be difficult to obtain a truly representative random sample and some species of animal are known to have different patterns of diurnal and nocturnal fecal excretion (24). Nevertheless, an assessment of random samples for accurate balance work in man will be worthwhile, if the inert indicator technique becomes widely adopted, since random samples might enable some balance investigations to be accurately performed outside of metabolic units, even though fecal collections in general hospital wards are so often incomplete.

Another advantage, which the inert indicator method has over both "time-collection" and "time-marker" studies, is the shorter time that a patient needs to be kept on a particular balance regimen. Because of the known variability in the frequency and amount of human daily fecal excretion, six-day periods of balance study have been recommended (12). This means that the minimum length of hospital stay for investigation of a single variable (e.g., the response of a patient to a low calcium diet) is at least 18 days, and with the "time-marker" method the duration of hospital stay will be further prolonged, while awaiting the passage of the second dose of marker. Our experience with $\mathrm{Cr}_{2} \mathrm{O}_{3}$ has convinced us that, after an adequate preliminary period on the balance regimen, it is practicable to base each investigation on two collection periods, each of three days, although a third three- 
day period would act as a safeguard by revealing the presence of a trend due to some unforeseen and uncontrolled variable in the experiment (12). Further, in contrast to "time-marker" studies, when delays in the passage of the marker often occur, the inert indicator technique has been found to help administratively, since it has proved possible to plan each metabolic study and forecast accurately the stay of each patient in the ward.

The main disadvantage of this technique has been the labor involved in the accurate filling of capsules with $\mathrm{Cr}_{2} \mathrm{O}_{3}$. With the inert indicator technique it is, however, essential that the intake of indicator be regular and accurately known, and patients' cooperation has been obtained by explaining that the capsules assist in the laboratory's analyses; nevertheless, one patient failed to cooperate in taking the capsules.

The requirements of an ideal fecal inert indicator were listed in the introduction and the present study supports the conclusion of earlier workers that $\mathrm{Cr}_{2} \mathrm{O}_{3}$ fulfills these requirements. Criteria for ensuring restropectively that a patient had attained a steady state with respect to dosage with $\mathrm{Cr}_{2} \mathrm{O}_{3}$ have been proposed, and the importance of preliminary periods of adequate length on any balance regimen has been emphasized. A note of caution should, however, be added at this point; although several cases of steatorrhea have been investigated (some with an average daily fecal fat excretion of 25 to $30 \mathrm{~g}$ ), none of the patients studied has been suffering from a gross disorder of intestinal motility. When intestinal motility is abnormal it is possible that "streamlining" of intestinal contents may occur; under such conditions the density of $\mathrm{Cr}_{2} \mathrm{O}_{3}$ might cause it to sediment and to be carried irregularly along the intestinal lumen. If this occurs, a steady value for the mean stool flow may never be obtained. In such patients (sprue is a possible example) an additional requirement for an ideal fecal inert indicator will have to be included, namely that it shall be uniformly dispersed with the intestinal contents throughout their passage in the gut, and polyethylene glycol might be more satisfactory than $\mathrm{Cr}_{2} \mathrm{O}_{3}$ under these circumstances. Extra care will be necessary in such patients, if fecal analyses are based on analysis of random samples, to ensure that the sample analyzed is truly representative.

\section{SUM MARY}

This article describes the application of chromium sesquioxide as an inert indicator in metabolic balance studies on 36 patients and 4 normal volunteers. The information gained by this technique is mainly considered in relation to four representative calcium balance investigations.

The inert indicator reveals the magnitude of fluctuations in the daily output of feces, when collections are made over both three-day and sixday periods; use of chromium sesquioxide corrects for these fluctuations. The technique also corrects for small losses of feces which occur even in "complete" fecal collections, and inclusion of an inert indicator in balance investigations acts as a safeguard against the major losses which occasionally occur in metabolic work.

The advantages of the inert indicator technique are considered in relation to simple "time-collections" and "time-marker collections" of feces, and it is proposed that balance investigations can be considerably shortened by its use. The wider application of inert indicators in connection with the analysis of random samples of human feces is considered.

\section{ACKNOWLEDGMENTS}

The authors wish to acknowledge the interest and advice of Professor Russell Fraser, and to thank him for permission to publish details of his patients. They are also very grateful to Dr. M. T. Harrison and Dr. I. D. P. Wootton for helpful discussions, and to Sister S. Cooper and the staff of the Metabolic Unit.

\section{REFERENCES}

1. Edin, H., Kihlén, G., and Nordfeldt, S. A summarized description of "Edin's indicator method" for the determination of the digestibility of feeds and feed mixtures. LantbrHögsk. Ann. 1944, 12, 166.

2. Stanley, M. M., and Cheng, S. H. Excretion from the gut and gastrointestinal exchange studied by means of the inert indicator method. Amer. J. dig. Dis. 1957, 2, 628.

3. Kane, E. A., Jacobson, W. C., and Moore, L. A. A comparison of techniques used in digestibility studies with dairy cattle. J. Nutr. 1950, 41, 583.

4. Fournier, P. De l'emploi de l'oxyde de titane pour l'étude quantitative de l'absorption intestinale. C. R. Acad. Sci. (Paris) 1950, 231, 1343. 
5. Sperber, I., Hydén, S., and Ekman, J. The use of polyethylene glycol as a reference substance in the study of ruminant digestion. LantbrHögsk. Ann. 1953, 20, 337.

6. Kreula, M. S. Absorption of carotene from carrots in man and the use of the quantitative chromic oxide indicator method in the absorption experiments. Biochem. J. 1947, 41, 269.

7. Irwin, M. I., and Crampton, E. W. The use of chromic oxide as an index material in digestion trials with human subjects. J. Nutr. 1951, 43, 77.

8. Stanley, M. M., and Cheng, S. H. Cholesterol exchange in the gastrointestinal tract in normal and abnormal subjects. Gastroenterology 1956, 30, 62.

9. Borgström, B., Dahlqvist, A., Lundh, G. and Sjövall, J. Studies of intestinal digestion and absorption in the human. J. clin. Invest. 1957, 36, 1521.

10. Lundh, G. Intestinal digestion and absorption after gastrectomy. Acta chir. scand. 1958, suppl. 231, 15.

11. Hydén, S. A turbidimetric method for the determination of higher polyethylene glycols in biological materials. LantbrHögsk. Ann. 1956, 22, 139.

12. Reifenstein, E. C., Jr., Albright, F., and Wells, S. L. The accumulation, interpretation, and presentation of data pertaining to metabolic balances, notably those of calcium, phosphorus, and nitrogen. J. clin. Endocr. 1945, 5, 367.

13. King, E. J., and Wootton, I. D. P. Microanalysis in Medical Biochemistry, 3rd ed. London, J. and A. Churchill, 1956, pp. 135, 183.

14. Hodgman, C. D., Weast, R. C., and Selby, S. M. Handbook of Chemistry and Physics, 40th ed.
Cleveland, Chemical Rubber Publishing Co., 1958, pp. 541, 563.

15. Vogel, A. I. A Text-Book of Quantitative Inorganic Analysis: Theory and Practice. London, Longmans, Green, 1939, p. 366.

16. Report by the Metallic Impurities in Organic Matter Subcommittee (Analytical Methods Committee). Notes on perchloric acid and its handling in analytical work. Analyst 1959, 84, 214.

17. Smith, G. F. The dualistic and versatile reaction properties of perchloric acid. Illustrative experimental demonstration procedures. Analyst 1955, 80, 16.

18. Furness, W. The determination of chromium in chromite. Part I. Volumetric determination of chromate with special reference to the effects of vanadate and arsenate. Analyst 1950, 75, 2.

19. Stockdale, D. The estimation of iron by dichromate. Analyst 1950, 75, 150.

20. Gorsuch, T. T. Radiochemical investigations on the recovery for analysis of trace elements in organic and biological materials. Analyst 1959, 84, 135.

21. MacIntyre, I. The flame-spectrophotometric determination of calcium in biological fluids and an isotopic analysis of the errors in the Kramer-Tisdall procedure. Biochem. J. 1957, 67, 164.

22. Gubler, J. A., and Kukral, A. J. Barium appendicitis. J. int. Coll. Surg. 1954, 21, 379.

23. Young, M. O. Acute appendicitis following retention of barium in the appendix. Arch. Surg. (Chicago) 1958, 77, 1011.

24. Mueller, W. J. Feasibility of the chromic oxide and the lignin indicator methods for metabolism experiments with chickens. J. Nutr. 1956, 58, 29. 